\title{
Venture Capital Performance: The Disparity Between Europe and the United States *
}

\author{
Ulrich Hege ${ }^{\dagger}$ \\ HEC Paris \\ Frédéric Palomino \\ ENSAE \\ Armin Schwienbacher $\$$ \\ University of Amsterdam Business School \& Catholic University of Louvain
}

January 2008

\footnotetext{
${ }^{*}$ We would like to thank Catherine Casamatta, Bruno Crepon, Didier Guennoc, Michael Halling, Jan MahrtSmith, Marco Pagano, Henri Pages, and Alessandro Sembenelli as well as seminar audiences at the European Finance Association, the First RICAFE Conference, the Journees Banque de France, the Gutmann Center Symposium in Vienna and the University of Toulouse for helpful suggestions. We gratefully acknowledge financial support from the Fondation Banque de France and the European Commission (Contract HPSE-CT-2002-00140) as well as support from the European Venture Capital Association.

${ }^{\dagger}$ HEC School of Management Paris, Dept. of Finance and Economics, 1 rue de la Liberation, 78351 Jouy-enJosas, France. hege@hec.fr, Tel. +33 139677299.

${ }^{\ddagger}$ ENSAE, 3 avenue Pierre Larousse, 92245 Malakoff Cedex, France. frederic.palomino@gmail.com, Tel. +33 1 55040005 .

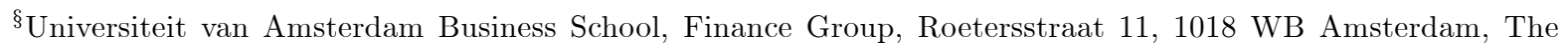
Netherlands. a.schwienbacher@uva.nl, Tel. +31 205257179.
} 


\title{
Venture Capital Performance: The Disparity Between Europe and the United States
}

\begin{abstract}
This paper compares the success of venture capital investments in the United States and in Europe by analyzing individual venture-backed companies and the value generated within the stage financing process. We document that US venture capitalists generate significantly more value with their investments than their European counterparts. We find differences in contracting behavior, such as staging frequency and syndication, and evidence that they help to explain the observed performance gap and we report a substantial unexplained residual. We find that US venture funds investing in Europe do not perform better their European peers. European Common Law and Civil Law countries exhibit comparable levels of venture performance, and differences in stock market development or tax subsidies in favor of venture investments are unrelated to performance differences. European IPO exits from venture investments yield returns similar to the US, while trade sale exits weakly underperform. We attribute the overall performance gap essentially to the segment of poorly performing companies.
\end{abstract}

Keywords: venture capital performance, financial development, stage financing, exit, monitoring.

JEL classification: G24; G38. 


\section{Introduction}

Venture capital is an American invention, and the United States is home to the largest venture capital industry by far. Venture capital has not spread globally as easily as have other financial innovations. What are the necessary conditions for a successful imitation of the US model? Europe, the world's second most important region in terms of R\&D spending, is an interesting case to consider. While European governments have exhorted the virtues of venture capital, and designated its development as a key policy priority for more than twenty years, the sector has remained a laggard until recently. A European venture capital (VC) industry geared towards innovation and early-stage financing has really only taken hold in the late 1990s, with investments reaching 12 billion dollars in 1999, roughly a quarter of the US level.

This paper proposes a direct comparison between the United States and Europe, and seeks to explore the process by which VC creates economic value on the basis of company-level data. It contributes to an emerging literature on comparative international studies of venture capital by focusing on possible obstacles to the emergence of a VC industry in developed countries with relatively high levels of R\&D spending, investor protection, and law enforcement.

Trade associations and VC professionals have long asserted that realized returns of venture investments in Europe have historically been below required returns, and pointed to this underperformance as the main obstacle to the development of a strong VC industry. Also, the relative lack of venture funding in Europe has been frequently attributed to the absence of attractive and liquid markets for VC exits, in particular for IPOs (e.g., Black and Gilson, 1998). These beliefs form the starting point for our analysis. We investigate whether a measurable performance gap between the United States and Europe exists for the late 1990s when the European VC market was emerging in terms funding levels and exit opportunities. And if so, what explains it? Does the European case hold more general lessons for venture capital development?

More specifically, we investigate the period between 1997 and 2003, starting with the year that marks the beginning of rapidly increasing venture funding levels in Europe and ending after European venture investments had peaked. Our focus on this recent period also offers an opportunity to address Black and Gilson's hypothesis on the absence of sufficiently liquid primary 
equity markets, since this period was characterized in Europe by a surge in high-tech IPOs as well as the creation of a number of new stock markets geared to high-tech companies markets. To the best of our knowledge, no comparative analysis of US and European VC performance has been undertaken previously.

Research Design and Results. Based on data from the Venture Economics database, we measure the value generated by every portfolio company in our sample by the Internal Rate of Return (IRR) between the first financing round and the last round valuation (prior to exit) of the project. Round valuation data represent an intriguing data source in $\mathrm{VC}$ funding as they report the deal pricing in every financing round, i.e. actual transactions between stakeholders with conflicting interests that determine the fraction of equity-linked securities afforded to investors in exchange for their cash. Determining VC success on the basis of round valuations offers a methodological advantage when compared with the alternative, analyzing performance until exit: performance measures based on exit valuations will inevitably select only projects that exit with a recorded market valuation; these investments, however, typically constitute an upwards biased sample. Moreover, since we are interested in the economic value generated by venture investments rather than an assessment of the asset class, our method seems well-suited as it allows to compute the gross valuation effect of venture investments rather than net cash disbursements to limited partners on which asset management studies focus. The focus on round valuations also allows us to perform new tests for data endogeneity based on lead-lag structures of intermediate valuations.

While our focus on early stage investments clustered in a few industries and a limited time period partially mitigates the impact of cross-sectional heterogeneity in risk, we explicitly control for risk, in particular for region-specific and technology-specific risk, but find results that are largely invariant with respect to the choice of risk adjustment. Our main results are the following.

- Our data show a gap between the value generated by US venture capital investments and European investments that is statistically highly significant and very large in economic terms. The difference is independent of the choice of performance benchmark.

- We observe several differences in the relationship between VCs and entrepreneurial firms and in their behavior that indicate a more active role of US VCs and a sophisticated cooperation between them. US venture capitalists invest almost twice as much in their portfolio 
companies, make a larger portion of funding contingent on the completion of the first round, organize themselves in larger syndicates, tend to involve corporate VC more frequently, and tend to be more specialized.

- These differences can partially explain the observed difference in value creation. We find the positive relationship between the frequency of monitoring and performance that theory predicts for the US but a negative relationship in Europe. Also, the amount invested in the first round as well as the presence of corporate VC (dimensions where the US dominates) have a significant positive impact on returns. Much of the performance gap, however, remains unexplained by such differences.

- US venture funds investing in Europe do not create more value than their European peers.

- Venture investments in European Common Law and European Civil Law countries show a comparable level of value creation.

- Differences in the tax treatment or the legal environment for venture investments are unrelated to the gap in value creation.

- For the subsample of companies with a successful venture exit, we find no performance difference for companies exiting through IPOs and only a small difference for companies exiting via trade sales. We conclude that the difference in the value creation process must be primarily due to differences in poorly performing investments as we find.

Overall, our results suggest that the United States appears to have a markedly better developed market for VC, with Europe still significantly lagging behind. We test for a wide variety of possible reasons that the finance literature mentions as possible performance drivers, but find that only contracting proxies can explain some of the difference, while causes such as tax treatment, legal systems or stock market development, or the import of experienced VCs, seem to be unimportant. Other factors that our microlevel study based on VC transactions cannot capture may be important. ${ }^{1}$

\footnotetext{
${ }^{1}$ These factors could include, among others, the presence of clusters of innovative activity, research output and spillovers from research universities and organizations, cultural attitudes towards risk and propensity to entrepreneurship.
} 
Related Literature. Our work is related to an emerging literature on international and comparative studies. On the whole they report VC contracting practices at variance with the US role model. Lerner and Schoar (2004) look at emerging markets in Eastern Europe and elsewhere and find a strong reliance on straight equity and direct board control. Cumming, Schmidt and Walz (2004) show that an increase in legality accelerates the first investment, and facilitates syndication and board representation of venture investors for a sample drawn from North and South America, Asia and Europe. Similarly, Cumming, Fleming and Schwienbacher (2006) find evidence for Asia-Pacific in support of the relevance of legal systems for exit choices. Cumming and Walz (2004) report that variables capturing VC, entrepreneur and investment characteristics can account for a substantial fraction of cross-sectional return variations in IRRs. Our findings are generally consistent with these studies, but we try to explain internal rates of return simultaneously by company-specific and country-specific influences. This puts us in a position to argue that contracting features and the legal environment alone are unlikely to explain the distance to the United States.

The majority of empirical studies on VC in Europe are based on questionnaires. In a crosscountry analysis, Manigart et al. (2002) highlight some determinants of required returns on VC investments, and Sapienza, Manigart and Vermeir (1996) examine the impact of the VC governance structure in different countries. Bottazzi, Da Rin and Hellmann (2004) show that independent, specialized, experienced and highly educated VCs are more likely to be actively involved in the management of portfolio companies. Bottazzi, Da Rin and Hellmann (2005) present questionnaire evidence that across Europe better legal systems (measured by legal origin or rule of law) are associated with more investor involvement, more downside protection for the investors, and more corporate governance involvement of VCs. Schwienbacher (2004) analyzes the determinants of VC exit decisions in a comparison of US and European VC firms and finds significant differences, for example on the use of convertibles and syndicate size, confirming and extending findings of Bascha and Walz (2001) for Germany. Da Rin, Nicodano and Sembenelli (2006) study the evolution of aggregate VC investments in fourteen European countries as a function of policy measures and find a significant impact of the creation of stock markets geared to entrepreneurial firms and of capital gains taxations. Mayer, Schoors and Yafeh (2005) investigate 
the funds raising process in various countries. Schmidt and Wahrenburg (2003) report that reputational effects of venture capitalists are a major determinant of contractual relations between European VC funds and their investors. Unlike our paper, these studies do not investigate VC performance directly.

There has also been a recent literature studying the returns of private equity and VC from an asset pricing perspective, including Kaplan and Schoar (2005), Gottschalg and Phalippou (2007), Ljungqvist and Richardson (2004), and Jones and Rhodes-Kropf (2004). On the whole, this literature shows that private equity returns contain considerable systematic and idiosyncratic risk and that risk-adjusted net returns do not outperform public equity investments. ${ }^{2}$ There are considerable differences between this strand of work and our study. First, these studies focus on the United States and they mix VC and private equity investments whereas our study is very careful in selecting only VC investments in start-up companies. Second, since our focus is on economic value created rather than risk-adjusted investor returns, we look at investments at the portfolio-company level and we use stage valuations to minimize selection bias. By contrast, these studies look at returns at the fund level, ${ }^{3}$ they focus on cash distributions and thus on exited investments. ${ }^{4}$ Third, we focus on an international comparative study in which the US and the European samples are selected according to consistent criteria, whereas those studies have overwhelmingly US-based samples.

Therefore, from a methodological point of view, our paper is most closely related to two studies that calculate company-level returns for venture-related investments, namely Cochrane (2005) and Woodward and Hall (2003). Both studies, however, use samples that exclusively contain US companies. Moreover, both studies are interested in understanding the risk-return trade-off, and their focus is on reducing the impact of sample selection bias. They do not explore

\footnotetext{
${ }^{2}$ Moreover, Kaplan and Schoar (2005) and Gottschalg and Phalippou (2006) show that US funds show significant return persistence, and Jones and Rhodes-Kropf (2004) find evidence that returns are correlated with idiosyncratic risk. Besides, there is considerable variation in scope and results across those four papers. More precisely, Kaplan and Schoar (2005) and Jones and Rhodes-Kropf (2004) find an insignificant average alpha whereas Gottschalg and Phalippou (2006) report a negative alpha. Ljungqvist and Richardson (2004) do not analyze risk-adjusted performance explicitly but find returns that are comparable.

${ }^{3}$ Kaplan and Schoar (2004), Gottschalg et al. (2004), Ljungqvist and Richardson (2004) and Jones and RhodesKropf (2004) all undertake fund-level performance analyses.

${ }^{4}$ Kaplan and Schoar (2005) and Gottschalg and Phalippou (2006) make different assumptions on non-exited investments that explain a substantial part of the difference in the aggregated performance estimates between these two studies.
} 
performance drivers. Cochrane calculates returns for each financing round separately and limits the sample to final valuations from IPOs and trade sales, whereas we take an integrated approach that solicits as many observations as possible at each round. Woodward and Hall (2003) include round valuations just as we do, but they do not systematically research the impact of various contractual features on VC performance.

The rest of the paper is organized as follows. Section 2 presents the theoretical and empirical background for our study. In Section 3 we describe the data and develop the variables used in our empirical tests. Section 4 presents the results of our comparative performance study. In Section 5 we investigate whether the performance gap can be attributed to differences in the use and success of various exit routes. Section 6 discusses issues of robustness, selection bias and endogeneity. Finally, Section 7 concludes.

\section{Theoretical and Empirical Background}

Two strands of prior work are relevant for our hypotheses, the mostly theoretical literature on the contractual relationship between venture financiers and entrepreneurs, and the mostly empirical literature that analyzes venture financing in the wider context of financial development.

\subsection{Venture Capital Contracting}

Monitoring, Advising and Relationship Financing. Venture capitalists are usually seen as actively involved relationship investors, and their monitoring role and the ensuing double agency problems have been emphasized by Schmidt (2003) and Cornelli and Yosha (2003), Repullo and Suarez (2004), among others, a view supported in empirical studies (Gompers and Lerner, 1999). More specifically, they are seen as taking on a dual role as advisors and as monitors (e.g. Casamatta, 2003) and as being actively involved in constituting the management team and frequently replacing the founding entrepreneurial team (Hellmann, 1998). Therefore, measures of a more active involvement of VCs in a project should be associated with more value creation.

We specifically investigate the relationship character of the link between VCs and portfolio companies. In this respect, we investigate two distinct hypotheses that can be characterized as 
the conflict between relationship building versus specialization. On the one hand, along the lines of the financial intermediation literature (e.g. Rajan, 1992), more continuity of VCs (over the entire project lifetime) means a closer relationship that reduces asymmetric information hurdles to financing. This should increase observed average performance. On the other hand, VCs may be specialized to accompany either initial stages or stages close to exit; specialization then clearly may be a source of value creation, as VCs presumably are more expert in the stage-specific skills of their contribution. Therefore, we will test whether a larger degree of continuity or a longer duration in the VC company relationship increases or decreases the value creation over the lifetime of the $\mathrm{VC}$ investment cycle in a project.

Based on the seminal contribution by Aghion and Bolton (1992), the literature has emphasized that contingent control rights, such as the use of contingent securities or contingent voting rights, play an important role in the VC cycle and value creation process. Schwienbacher (2004) directly compares the use of contingent control rights in the United States and in Europe, and finds that they are significantly more common in the United States than in Europe, consistent with the predictions of Bottazzi, Da Rin, and Hellmann (2005) and with other empirical evidence. ${ }^{5}$ There is no clear evidence, however, that these differences directly explain VC performance. Our data do not allow us to contribute to this important analysis as we do not observe details on the securities that are issued in the financing rounds.

Stage Financing. The theory literature suggests that stage financing gives a real option to abandon a project that alleviates agency problems. In Neher (1999), stage financing can reduce the bargaining power of entrepreneurs who can repudiate their financial obligations. Cornelli and Yosha (2003) analyze the problem of an entrepreneur manipulating short-term results for purposes of "window-dressing" and show that stage financing is a means to mitigate this problem. Berk, Green and Naik (2004) focus on the evolution of the risk profile that changes from being purely technical risk in early stages and to more diverse sources of risk in later stages and show that the systematic risk component is strongest in early stages, justifying a larger risk premium.

\footnotetext{
${ }^{5}$ Additional evidence on the less frequent use of contingent securities outside the US is documented for example in Kaplan, Martel and Stromberg (2003), Lerner and Schoar (2005), Cumming (2005) and Bascha an Walz (2001), when comparing them to US studies. An important alternative hypothesis is proposed by Gilson and Schizer (2002) who attribute the frequent use of convertibles in the United States to tax considerations.
} 
Elitzur and Gavious (2003) and Bergemann and Hege (2003) suggest that stage financing reduces the entrepreneur's information rent, and allows to increase entrepreneurial effort and alleviate financial constraints. Cuny and Talmor (2005) compare traditional round financing with milestone financing, where VCs commit to the financial terms of multiple funding stages conditional on achieving certain benchmarks. ${ }^{6}$ All of these papers, and a host of empirical literature (for example Gompers, 1995), suggest that a higher frequency of milestones and financing rounds should translate into a more effective use of the abandonment decision, and hence smaller agency costs and better investment performance. Therefore, we will test whether a more frequent use of staging instruments implies higher performance.

Syndication and Corporate Venture Funding. Besides the obvious motive of risk diversification, leading motives for VC syndication mentioned in the literature are (i) improved screening by securing a second opinion in the due diligence process (Casamatta and Haritchabalet, 2007; Cestone, Lerner and White, 2005); (ii) complementarities in the monitoring and advising of companies (Bruining, Verwaal, Wright, Lockett and Manigart, 2005) and (iii) the sharing of information and pooling of contacts in the exit phase. These reasons imply that syndication should have a positive impact on measurable performance. Hochberg, Ljungqvist and Yang (2007) find indeed evidence that VC firms with better network connections established through their position in syndicates have significantly better performance. Therefore, we test whether measures of value creation are positively correlated with the extent of syndication.

A related question is the relationship in a syndicate between experienced or highly reputed VCs and comparatively young and small ones. The theory literature is not unanimous in this respect. Barry et al. (1990) emphasize the certification and reputation gains when syndicating with more experienced VCs, suggesting that syndicates will combine young with experienced VCs. On the other hand, Cestone, Lerner and White (2005) argue that agency conflicts between VCs lead to assorted matches of VCs joining forces with other VCs of comparable screening and monitoring abilities. In our context, since European VC firms tend to be considerably younger,

\footnotetext{
${ }^{6}$ Cuny and Talmor (2005) show that the milestone financing dominates round financing when venture capitalists' effort is relatively small, the funding volume decreases (relatively) over time or if there is heteregeneity in beliefs between financiers and entrepreneurs. Their predictions are difficult to test, however, as most venture capital arrangements combine milestones and round financing and milestones are only imcompletely observed.
} 
we investigate the difference between homegrown European VC firms and US venture capitalists operating in Europe as an important measure for such differences in experience.

Moreover, syndication facilitates the inclusion of corporate investors that can act as a commitment device to avoid hold-up problems and help secure distribution channels or a potentially important customer pool, see e.g. Hellmann (2002) and Riyanto and Schwienbacher (2006). The corporate venture fund can also provide additional complementary skills to the syndicate as well as important resources from the corporation that backs it. Therefore, we also explore the value impact of the presence of corporate $\mathrm{VC}$ in the investor pool. ${ }^{7}$

\subsection{Financing of Innovation, Financial Development and Tax Incentives}

Based on previous literature that analyzes conditions for $\mathrm{VC}$ and the financing of innovation in a wider context, we explore the following aspects.

IPO Exits. Black and Gilson (1998) identify the lack of IPO markets for VC exits as the main reason why venture financing lags behind in countries such as Germany or Japan. Portfolio companies where venture investors exit through IPOs are generally associated with higher returns (see Gompers, 1995, for the US and Schwienbacher, 2004, for Europe). While historically Europe offered little opportunity for high-tech firms to go public, the creation of technology-oriented stock markets in all of Europe's main countries in the late $1990 \mathrm{~s}^{8}$ has created a more even field between the US and Europe, at least for the period of time where these new markets offered a fairly liquid alternative for VC exits. ${ }^{9}$ Therefore, we would expect a relatively equal VC performance in Europe and the US for ventures that exited during the liquid IPO market in Europe, i.e. 1998-2000.

Stock Market Development. Rajan and Zingales (2003) and Black and Gilson (1998) identify the importance of market-based financing, and in particular the role of stock exchanges, as a key determinant for successful venture development. This hypothesis suggests that we should find a higher intensity and also higher returns of $\mathrm{VC}$ funding in countries with a high stock market

\footnotetext{
${ }^{7}$ Other rationales for venture capital syndication are provided by Admati and Pfleiderer (1994) and Lakonishok, Shleifer and Vishny (1991).

${ }^{8}$ The German Neuer Markt, the French Nouveau Marché, London-based Techmark and Brussels-based Easdaq are the best-known examples, which all broadly used the Nasdaq as their role model.

${ }^{9}$ In the wake of the collapse of the internet boom, a number of these markets have ceased to exist or been merged with the main stock markets (Easdaq and the Neuer Markt for example), whereas others continue to exist but had very little IPO activity between 2001 and 2004.
} 
capitalization/GDP ratio, the most widely used metric of stock market development. Since Europe contains both countries with a higher ratio of stock market capitalization to GDP than the US (UK, Netherlands, Switzerland) as well as countries with a lower ratio (most countries on the continent), there is sufficient variation in the data to make this a rich test.

Law and Finance. Following the seminal work by La Porta et al. (1997, 1998), legal origin has been explored as an explanatory variable in many studies of financial performance. The quality of law enforcement has also been emphasized as a determinant. Given that contracting problems are pervasive in the financing of innovation, $\mathrm{VC}$ should be particularly affected by these concerns. Lerner and Schoar (2004) find evidence, in a sample of private equity investment in emerging markets, that both legal origin and an index of law enforcement (time-to-decision) seem to matter for the contractual relationships between venture investors and portfolio companies. Cumming, Schmidt and Walz (2004) show that higher standards of legality translate into more control rights for VCs. In a theoretical model that specifically addresses VC, Bottazzi, Da Rin, and Hellmann (2005) derive comparative statics results that predict that, in a better legal system, investors provide more value-adding support, demand more contractual 'downside' protection, and are more active in exercising corporate governance rights. All these results suggest that a higher degree of legal investor protection translates into better venture performance.

Tax Subsidies for Venture Capital and Related Fiscal and Legal Conditions. Many European governments offer tax subsidies or similar incentives for VC investors (like capital guarantees in Germany and Austria), or incentives for venture-backed entrepreneurs like a generous capital gains taxation. Such public subsidies may be a source of underperformance if they distort investment decisions and make VCs inclined to fund projects that they would otherwise reject (see Lerner, 1999). We hypothesize, therefore, that measures of fiscal subsidies and related supports to venture funding may be negatively related with performance.

\section{Data}

Our data set is constructed from the database of Venture Economics, a division of Thomson Financial. Venture Economics offers the best available database for performance-related data on 
European VC markets, even though the reporting is substantially less complete than on the US side. For Europe, we extract from this database all portfolio companies for the 15 countries that were member of the European Union during the period of our study (EU-15). Since the paper focuses on venture capital, we limit the search to all companies that are reported as venture capital-related in the database (i.e. we exclude notably buyout- and restructuring-related transactions). We then require that Venture Economics report at least one valuation observation for a portfolio company, i.e. the estimated total value of the company firm at one or more financing stages. Firm valuations are the reported values on which the contracts and share allocations at the beginning of each new financing round are based. We obtain a sample of 394 companies. Among them are 188 from the United Kingdom, 65 from France, 51 from Germany, 25 from Ireland, 16 from Italy, 12 from Sweden, 11 from the Netherlands, 11 from Belgium, 7 from Spain, 5 from Denmark and 3 from Austria.

To correct for possible misclassifications of firms in the Venture Economics's venture capitalrelated database, we remove from the sample all companies that have neither a single round that was defined as "seed" or "early stage" in the database nor at most three years of age at the time of their first financing round. Our objective is to avoid comparing different types of investment on both sides of the Atlantic. Therefore, we also apply a filter restricting the sample to companies with a first financing round not earlier than January 1997, and drop a couple of outliers based on pre-financing size or age, leaving us with 274 observations.

Our focus on early stage investments that are clustered in a few industries and that span a short time window of seven years largely reduces the role of any important heterogeneity in project risk. Nevertheless we include explicit controls for risk. First, we choose a risk adjustment that specifically addresses regional differences in risk between the US and Europe by calculating excess returns relative to the MSCI index in each region. Second, we choose the NASDAQ index as an alternative risk adjustment that controls for the asset class of high-tech companies. In the absence of any comparable high-tech stock market index for Europe, we cannot control for both sources of risk simultaneously. We find that our results are virtually identical under both risk adjustment procedures, leading us to conclude that the specific choice of risk adjustment is irrelevant for the results that we report. A third possible risk adjustment, namely industry-specific risk, seems 
impracticable for our sample given that it is dominated by very few industries. Therefore, we only control for firms that are either internet specific or in Communication and Media.

We also need to exclude companies for which a performance measure could not be calculated for lack of data. These are companies for which we had only a single valuation observation and where this valuation concerned the first financing stage. These companies were dropped from the sample. Our final sample contains 146 European companies, 71 of them being from the United Kingdom and 75 from Continental Europe or Ireland.

For the United States, we construct a random sample of comparable size. We apply the same filtering criteria as for European companies, limiting the sample to venture-related portfolio companies for which there is at least one valuation entry recorded (close to 6000 as of June 2003), that have at least one financing round that is characterized as "seed" or "early stage", and where the first financing round took place in or after January 1997. We then randomly select a sample of 233 companies that satisfy the criterion that at least two valuations are reported, of which one in the initial round.

Additional data sources complementing our data include the tax and legal index developed by the European Venture Capital Association (EVCA, 2003) ${ }^{10}$; World Bank data for 1997 for country measures of stock market capitalization; and finally Dealogic, Lexis-Nexis, Factiva and national stock exchanges as sources on exits and exit valuations.

\subsection{Description of Variables}

For all the companies in our sample, we extract the following information from the Venture Economics database: the age of the firm at the moment of the first financing stage, the activity of the firm, and for each financing stage, the date at which it took place, the type of the investors (public, corporate or financial), the amount they have invested and the post-money valuation of the firm. From this information, we define variables that can be grouped as follows:

Portfolio company characteristics. We capture company age by defining a variable AGE as the time lapsed between its founding date and the date of its first financing round. For industry

\footnotetext{
${ }^{10}$ The EVCA index attributes a score to European countries since 2003 (the first year where it is available) based on their tax subsidies for venture funding, corporate and personal income tax rates and capital gains taxation, as well as related legal conditions.
} 
affiliation, we group companies in seven industry groups. ${ }^{11}$ Information about the industry in which the company operates is captured by the dummy TMT which is equal to 1 if the activity of the firm is either internet specific or Communication and Media, and 0 otherwise.

Lifetime variables. First, we define the total duration between the first and the last stage (TOTALDURATION) and the number of stages (TOTALSTAGES). The ratio between these two variables gives a measure the frequency of financing rounds (AVG DURATION). We frequently use the notation $N$ for the value of TOTALSTAGES. Second, we define the variable AVG CONTI which represents the average continuity of investors. AVG CONTI is constructed as follows. For each stage $n \geq 2$, we compute the number of times that $V C$ s participating in stage $n$ participated in previous stages. This number is then divided by $(n-1)$ times the number of $V C$ s participating in stage $n$. We obtain $\operatorname{CONTI}(\mathrm{n})$, and we can then define AVG CONTI as $\left[\sum_{n=2}^{N} \operatorname{CONTI}(\mathrm{n})\right] / N$, which is a measure of the average fraction of continuing VCs in each of the $N$ financing rounds. Third, we define the variable AVG SYNDICATE SIZE which represents the average number of funds invested in each stage. It is constructed as follows. For each stage $n$, we compute the number of $V C \mathrm{~s}$ who participate in stage $n$ (SYNDICATE SIZE (n)). Then, AVG SYNDICATE SIZE is defined as $\left[\sum_{n=1}^{N} \operatorname{SYNDICATE} \operatorname{SIZE}(\mathrm{n})\right] / N$. Fourth, we define the variable AVG AMOUNT which represents the average amount invested in each financing round. For each stage $n$, we compute the total amount invested in stage $n$ (AMOUNT (n)). Then, AVG AMOUNT is defined as $\left[\sum_{n=1}^{N} \operatorname{AMOUNT}(\mathrm{n})\right] / N$. Finally, we define the variable CORP INVESTOR which is a dummy equal to one if there is a corporate investor, and 0 otherwise.

First stage variables. We use three initial stage characteristics: the amount invested in the first stage normalized by the average amount invested per round (AMOUNT STAGE 1), the number of investing funds in the first stage (SYNDICATE SIZE STAGE 1), and the duration of the first financing round (DURATION STAGE 1). We also use a measure of continuity of investment between the first two rounds (EARLY CONTI), which is a dummy equal to 1 at least one fund invested in both stages 1 and 2 , and 0 , otherwise.

Market conditions. We want to take into account market conditions, and more precisely the

\footnotetext{
${ }^{11}$ The seven industries are aggregated by following Venture Economics' industry classification (VEIC) system. Our seven industries are (1) internet (2) communication and media (3) computer software (4) computer hardware and semiconductors (5) manufacturing and other services (6) medical and health care and (7) biotechnology.
} 
so-called "internet bubble" on valuations and returns. To do so, we define two dummy variables: BUBBLE START and BUBBLE END. The former one is equal to 1 if the first stage took place between September 1998 and March 2000 and 0 otherwise, and the latter dummy is equal to 1 if the final valuation took place between September 1998 and September 2000 and 0 otherwise. ${ }^{12}$ We find similar results when using year dummies (omitted from the tables). In the analysis we further use the variable COMMON LAW that equal to 1 if the portfolio company is located in a Common Law country, and 0 otherwise. We also include the dummy variable EU DUMMY that is equal to one for European companies and zero for US investments.

\subsection{Summary Statistics}

We report summary statistics of the explanatory variables in Table 1. Test of differences in means between Europe and the United States are presented in Table 2.

Many sample characteristics are broadly comparable with earlier studies, and show no remarkable differences between the two samples. Projects go through 3.32 financing rounds on average and remain in a venture financing relation (until the last reported round) for a little less than two years. Roughly, half of the companies are in technology, media or telecommunications (TMT) and obtain their first financing within the September 1998-March 2000 period that we characterize as bubble. Almost a quarter of the US sample also exits in that period, four times more than in Europe. The first financing round amounts to $18.7 \%$ of firm value in Europe and $15.6 \%$ in the US. The median firm is one year old when receiving its first financing, and only $3 \%$ of companies are older than 7 years. European firms appear to be slightly older (2.45 v. 1.96 years in means and 1.27 v. 1.06 years in medians), but these differences are not significant.

We observe, however, highly significant differences along four dimensions. First, the total amount invested per project and the average amount invested per financing round are about 50\% larger in the United States than in Europe (significant at the $0.1 \%$ level). Interestingly, there is no difference in the initial financing round.

Second, European VCs exhibit a significantly larger continuity, in the sense that European

\footnotetext{
${ }^{12}$ September 1998 marks the end of Russian crisis, the last market downturn prior to the internet bull market, whereas September 2000 coincides with the peak levels of the NASDAQ index. Our results are robust to an alternative specification of the bubble period, or the inclusion of year dummies.
} 
VCs are more likely to participate in follow-up rounds, perhaps due to more severe informational problems. In contrast, US VCs are less likely to participate in follow-up rounds, leaving a larger role to new investors with possibly additional skills. When measured by AVG CONTI, the average fraction of continuing VCs, the continuity is significantly larger in Europe at the 1\% level. The same is true, albeit statistically weaker, for the measure of continuity between the first and the second round, EARLY CONTI.

Third, the average VC syndicate, over all rounds, includes 3.7 members in the United States but only 2.8 in Europe. This is a highly significant difference (at the $0.1 \%$ level). There is again no significant difference in the initial financing round. This observation seems consistent with the idea that VC networks in the US operate more efficiently and that US VCs have better tools to enforce cooperative behavior in syndicates than their European counterparts. It would also appear consistent with the notion that in a more mature VC market, VCs are more specialized, so that the observation of larger syndicates and less continuity might indeed be connected. Both observations suggest that US VCs can implement a more efficient division of labor among them than Europeans.

Finally, 36\% of VC-backed companies in the United States include a corporate investor in the syndicate at least one financing round, which is twice as many as in Europe (significant at the $0.1 \%$ level). This lends support to the idea that US VCs are more successful in integrating complementary industry expertise into the venture funding cycle.

These findings show that the contract characteristics of projects are different in the United States and in Europe, and differences concerning measures of the relationships among VCs and of the relationships between VCs and companies are the largest. Overall, the observed differences appear to document an edge of US venture capital firms over their European counterparts.

\section{Results}

\subsection{Performance Measures}

Our main measures of the return of each company are based on the first and the last observed valuation entry of the project (prior to exit). We first calculate the internal rate of return (IRR) 
of the project, by taking into account all intermediate investments. ${ }^{13}$ then, we follow the standard procedure and take logs of the IRR; the empirical frequency distribution of the resulting random variable LOG IRR exhibits an approximately normal distribution. ${ }^{14}$

One problem with the IRR and LOG IRR measures is that they calculate each projects' return in an isolated way, without adjusting for realized market returns and systematic risk. To adjust for the risk relative to the realized market return, we develop as a second return measure the excess return of the project compared with the reference market. For Europe, we calculate the excess return as the difference between the IRR and the MSCI Europe Index return over the same period while for the US, we calculate the excess return as the difference between the IRR and the MSCI US Index return over the same period. For log returns, we take logs of the MSCI returns and subtract them from LOG IRR to obtain the log excess return (LOG EXC) as our principal dependent variable.

For many companies, we only have one valuation observation. As explained earlier, we drop all observations where the unique valuation is in the first financing round. For those companies in our sample for which we observe only a single valuation at a round later than the first round, we estimate a value $\hat{V}_{1 j}$ for the first stage valuation of company $j$ as follows. For all the companies for which a valuation at stage 1 was available, we calculate a multiple $Q_{i}=V_{1 i} / I_{1 i}$ expressing the initial company value for company $i$ as a multiple of the initial investment. We then calculate an average ratio $Q_{k}$ for each of our seven industries $k=1, \ldots, 7$, as the equal-weighted mean of all the companies belonging to this particular industry. The observed $Q_{k}$ are actually slightly larger in Europe, but we use uniform $Q_{k}$ across which introduces a bias against our results. We then estimate the missing first-stage valuation $\hat{V}_{1 j}$ for a firm $j$ located in industry $k$ a the product $\hat{V}_{1 j}=Q_{k} I_{1 j}$. We find very similar results to those reported in our tables if we restrict the analysis to the $61 \%$ of companies in our sample with complete valuation information.

Summary statistics and comparisons between the Europe and the United States are given in Table 3. Data are winsorized at the $1 \%$ level to reduce the impact of the extreme return values.

\footnotetext{
${ }^{13}$ The IRR iscalculated as the rate $r$ such that $\frac{V_{T}}{(1+r)^{T}}-\sum_{t} \frac{I_{t}}{(1+r)^{t}}-V_{0}=0$, where $V_{T}$ is the final valuation, $V_{0}$ the initial valuation, and $I_{t}$ the investment amount in period $0<t \leq T$.

${ }^{14} \mathrm{Using} \operatorname{logs}$ is generally appropriate since raw returns are distributed asymetrically over the interval $(-100 \%, \infty)$. In the case of venture capital returns, this adjustment is indispensable since outliers with extreme IRRs close to $-100 \%$ or above $+500 \%$ occur.
} 
We observe that the mean and the median excess returns in the United States are $279 \%$ and $61.37 \%$, respectively. Comparatively, they are only $62.5 \%$ and $-25.19 \%$, respectively, in Europe. Both mean and median excess returns are significantly lower in Europe (at the $0.01 \%$ level). The same results hold when considering unadjusted returns, or returns measured in logs. ${ }^{15}$ It should also be added that $69 \%$ of European projects are below the median while only $39 \%$ of US projects are below the median (not reported in the tables). The significance level of our comparison of means and medians remains equally strong results if we compare raw returns without winsorizing.

Gottschalg and Phalippou (2007) argue that IRR may be a misleading performance measure as it does not account for differences in the investment horizon of projects or in the amount of funds invested. In our view, the concern about different investment horizons is important when $\mathrm{VC}$ is considered from an asset pricing perspective but less relevant for our study that focuses on economic value created. Moreover, we do not expect it to matter as the difference in total duration between Europe and the US is insignificant. As a robustness check, we consider alternative performance measures, in particular a profitability index with a $10 \%$ and a $20 \%$ discount rate following Phalippou and Gottschalg's (2007) work. In each case, we find that the results are entirely robust to the use of any of the alternative performance measures, with virtually unchanged significance levels (results not reported).

Two interesting observations emerge. First, we obtain the same results when we calculate returns separately for the UK and for all other European countries. This ensures that the low performance of Europe, when compared with the US, is not driven by underperformance in a single country, the UK, that is so dominant in the European sample. Second, it could be argued that our results are sample biased since the number of firms having their final valuation before March 2000 is significantly larger (at the $0.1 \%$ level) in the United States. This does not seem to be the case, however, as the results are unchanged if we consider only firms that had their last valuation after March 2000 (168 observations in the United States and 130 observations in Europe).

Based on these observations, we consider the widest possible variety of reasons that are mentioned in the finance literature as drivers of venture capital performance. A first possible expla-

\footnotetext{
${ }^{15}$ The reason why the $t$-test is less significant for the non-log rates of returns is the extremely high cross-sectional variance of realized IRRs in venture financing.
} 
nation is that US VCs are more skilled or more sophisticated, and are therefore able to ensure a steeper value creation process, either by superior skills in the screening of business plans, or because of more effective contributions via monitoring and advising. For example, US VCs should, on average, be more experienced because of the longer history of the industry in the US market. In this respect, Kaplan, Martel and Stromberg (2003) and Lerner and Schoar (2004) document that US VCs tend to apply the same contractual methods tested and used domestically when investing abroad. For all these reasons, US VCs active in European projects should outperform their European-grown peers. To test for this hypothesis, we split the European sample into projects where at least one US-based venture capitalist was involved (hence contribute to the value creation process) and those where only European investors were present in all financing rounds. There are 97 European projects in which a US VC was involved. The performances of firms from these two sub-groups of European projects are not significantly different at the $10 \%$ level (See Table 3, Panel C). We also find that the average Log Excess Return of European projects with US VC is lower than the average Log Excess Return for of US projects at the $0.1 \%$ level (not reported in the tables). To test further the possible impact of US VCs on the performance of European projects, we sort out European projects in which more than $20 \%$ of the involved VCs are US VCs. There are 59 such projects. Their average Log Excess Return is -0.3490 . There are 88 other European projects. Their average Log Excess Return is -0.3471. Again, the average performances in these two subgroups are not statistically different at the $10 \%$ level. Hence, we do not find any evidence that the lower performance of US-based projects is due to the absence of the experience of US venture capitalists, ${ }^{16}$ and the explanation for the performance gap must be sought elsewhere. In our view, this finding does not contradict earlier evidence on the more sophisticated behavior of US venture capital providers abroad compared to local funds. They could for example indicate that distance and geographical proximity are important and hard to overcome as an effective barrier to the international expansion of venture capital development.

A second plausible explanation is whether the legal system in which a start-up company operates has an impact on its performance (see, e.g., La Porta et al., 1997, 1998). While there are various dimensions of differences in legal systems that vary across Europe, we are unable to imple-

\footnotetext{
${ }^{16}$ We also try different specifications of the implication of US venture capitalists, such as measures of the fraction or continuity of their involvement in European syndicates, with the same negative result.
} 
ment tests for differences such as legality/absence of corruption and quality of law enforcement, because our sample is heavily concentrated in North and Western European countries that exhibit little variation along these dimensions. We can, however, test for the legal origin. To do so, we split our European sample into companies from Common Law countries (UK and Ireland) and companies from Civil Law origins (all other countries). ${ }^{17}$ Testing for difference in performances, we do not find evidence that projects from Common Law countries obtain a higher return than those from Civil Law countries (see Table 3, Panel D). Rather, we find weak evidence of a smaller median performance in Common Law countries. This suggests that legal origin can be ruled out as a determinant of the performance gap.

Finally, the performance difference could be owed to cross-country differences in financial development (with stock market capitalization as the leading indicator) or to differences in tax treatments. We explore these avenues in the context of our regression analysis.

\subsection{Multivariate Regression Analysis}

Having highlighted differences in performances between US and European projects, we perform standard OLS regressions in order to find out which characteristics influence the performance of a firm, and find whether they provide a rationale for the difference in performances observed between the United States and Europe. First, we perform three types of regression for the entire sample. The first regression considers firm specific information and market conditions. The second regression adds conditions about the first financing stage while the third regression considers firm specific information, market conditions and contract variables that should be play a role during the entire life cycle of the venture project. We also interact all these variables with the EU DUMMY variable to see whether they have a different impact on performance in Europe and in the United States. Then, we run the same types of regressions for European firms, excluding the EU DUMMY variable and adding the US VC dummy variable. For all the regressions, the dependent variable is LOG EXC, the logarithm of the excess return over the MSCI indices.

Results for the entire sample are provided in Table 4 that break down the measures of the

\footnotetext{
${ }^{17}$ Due to the small number of observations we cannot split the Civil Law sample into French, German or Scandinavian origin.
} 
contracting relationship in two parts: Table 4 a reports the regression for the variables that capture the conditions in the first financing round, whereas Table $4 \mathrm{~b}$ captures average conditions over the entire financing period. We observe that the EU DUMMY variable comes out highly significant at the $0.1 \%$ level in all regressions; it is the single most powerful variable in all the regression specifications that we ran.

Conversely, the COMMON LAW dummy variable does not come out significantly. These results confirm the findings of the $t$-test analysis of returns in Table 3. we also use several countryspecific variables. Table 4a documents that neither the stock market development (1997 market capitalization as a fraction of GDP) nor the EVCA tax and legal index ${ }^{18}$ show any measurable impact. We reject therefore our hypotheses that stock market development or tax subsidies and related conditions play a significant role in explaining the European underperformance over the sample period.

Concerning project size variables, we observe that the average project size (AVG AMOUNT) has a significant impact on performance. However, this impact is positive in the United States, suggesting economies of scale, while it is negative in Europe. AMOUNT STAGE 1 is also significantly negative at the $0.1 \%$ level. Since Europeans invest a significantly larger fraction of total investments in the first round, this suggest that the power of making funding conditional on milestones is weaker when more of the overall funds is provided up-front, and thus unconditionally.

Concerning contracting variables, an important finding is that the round duration variables, either measured by the average round duration (AVG DURATION) or the first round duration (DURATION STAGE 1), have significant impacts on performance of opposite sign in the United States and in Europe. For the United States, the round-duration-performance relationship is as theory predicts: shorter round imply more monitoring, hence better performance. The observed positive relationship observed for Europe is puzzling. It might suggest that European VCs are more reactive than proactive; in other words, European VCs tend to shorten funding intervals

\footnotetext{
${ }^{18}$ The EVCA index is an aggregate score for 2003 (the first year for which it is available) with the best score of 1.2 for Great Britain and the lowest score of 2.53 for Austria in our sample. Taking the EVCA criteria, we determine a score of 1.4 for the United States by our own calculations. The US obtains a score slightly lower than Britain (but higher than all other countries in Europe) notably because of relatively high corporate tax rates and lengthy bankruptcy procedures.

The EVCA score is an aggregate score over 13 measures of fiscal and legal conditions; we obtain similar results when we use only the score for tax subsidies towards venture investments.
} 
only when things turn wrong.

We find almost no impact for our measure of the continuity of funding relationships. If anything, there seems to be a slight advantage for specialization over ongoing relationships.

Results for the European sample are provided in Table 5. Results are identical to those of Table 4 concerning contract and market condition variables: the average round duration and the first round duration have an significant positive impact of the performance. Furthermore, the US VC dummy and the COMMON LAW dummy do not come out significantly, confirming the results of Table 3 .

Overall, we find evidence that contracting-related variables matter. They tend to come out with the sign predicted by theory in the United States, but with the wrong sign in Europe. These explanatory variables, however, cannot fully explain the differences in VC performance since the coefficient for the EU Dummy remains economically significant.

\section{Exit Choices and Venture Capital Performance}

The literature has long held that exit conditions are a key performance driver in venture financing, and the absence of an active IPO market for venture-backed companies has been viewed as the perhaps single most important reason for the late and timid development of venture financing in Europe (Black and Gilson, 1998). Moreover, there is ample evidence that the exit choices of venture-backed start-ups follow a clear performance hierarchy, with top-performing companies choosing IPOs, companies opting for trade sales on average performing less well, whereas troubled investments would see delayed exits or write-offs. Our objective in this section is to explore whether we find evidence for differences in exit performance or in the hierarchy of exit routes that could help to explain the transatlantic performance gap.

This question is particularly interesting for our sample period because, as argued in Section 2., a characteristic element from 1997 to 2003 is that new stock markets had opened across Europe modeled after the NASDAQ example that were geared up to high-tech start-ups, and that were successful almost instantly, in terms of the number of IPOs they could attract. Our hypothesis is, therefore, that the Black and Gilson argument of the role of a lacking IPO market, while 
historically true, was no longer applicable to this period. Conversely, if we find differences in the performance of venture-backed companies going public between the US and Europe, this might indicate that the existence of dedicated stock markets is not sufficient to create exit conditions conducive to venture financing.

To investigate these issues, we extend our observation horizon to include the exit stage, and we explore whether we find significant differences in the relative performance of the subsamples having opted for different exit options. Specifically, we construct samples of venture-backed companies in the US and in Europe having exited via an IPO or via a trade sale. We then seek to obtain data on exit valuations for these companies, and we calculate a new IRR for the complete venture capital cycle from the first investment round to exit that we call the "full venture cycle IRR", as opposed to the IRRs used so far that stopped at the last reported financing round.

Within our US sample of 233 randomly selected companies after 1997 described in Section 3., we are able to identify 32 companies that exited via an IPO (13.7\% of the US sample) and 52 trade sales $(22.2 \%)$ that occur between 1997 and early 2005 from Venture Economics. We find exit valuations for 29 of the IPOs (12.4\% of the US sample) and 32 of the trade sales (13.7\%), which together form our US exit sample. ${ }^{19}$ In Europe, we encounter the difficulty that the number of companies having exited through an IPO or a trade sale within our sample of 146 companies with sufficient valuation information is too small for a statistical evaluation. ${ }^{20}$ To overcome this problem, we go back to our base sample of European venture-backed companies obtained from Venture Economics with first rounds in the 1997-2003 period, and after applying the same filters as before we initially select all companies that are reported as exited through IPO or acquisition. Most of these companies had to be excluded previously because there was insufficient valuation information to determine an IRR based on round valuations. We then seek to obtain data on exit valuations for this sample, which yields a sample of 54 IPOs and 19 trade sales in Europe for

\footnotetext{
${ }^{19}$ The US exit valuations were all found in Venture Economics.

${ }^{20}$ In the sample of 146 European observations, we can identify only 8 IPOs with observable exit valuations, even though we search through a variety of additional data sources such as national stock markets and equity issues reported in Dealogic. We believe that there are two reasons for this scarcity of exit observations: first, the slump in the liquidity conditions on the exit markets after 2001 was more severe and more protracted in Europe than in the US. Second, a majority of the companies in the European sample start relatively late in the sample period, and many of them were not ready for exit before liquidity conditions on the exit markets worsened. We cannot exclude, however, a selection bias in the Venture Economics data base that relies on voluntary reporting.
} 
which we can estimate the IRRs over their full venture cycle. ${ }^{21}$

Table 6 contains the findings for the IPO and the trade sale sample. We ignore observations with a very short complete venture cycle (less than three months for IPOs and four months for trade sales) since they contain a disproportionate number of extreme outliers, and also because performance will reflect market conditions more than fundamentals if venture capitalists have such a short time to add value. The summary statistics show that, consistent with previous literature, companies that exit through IPOs exhibit a very high performance on average, with an annual IRR of $1,001 \%$ (median $160.7 \%$ ), and almost identical numbers for excess return relative to regional MSCI segment (mean 988.4\%, median 150.4\%). Companies exiting through acquisitions show a performance that is markedly lower, with a mean IRR of $93.3 \%$ (median $-8.8 \%$ ). When looking at excess returns, with a mean of $96.9 \%$ (median $0.6 \%$ ), returns are slightly higher, implying that trade sales are particularly affected by adverse market timing effects, that is, exits taking place under adverse market conditions. While there is considerable uncertainty because of small samples and an important in-sample variance, the means appear still high when compared with the average performance reported above in Section 4.. Thus, our findings appear to lend support to the concept of a performance hierarchy according to the exit path. ${ }^{22}$

Is this hierarchy a possible explanation for the strong performance gap between the US and Europe that we find? When we look at possible return differences in the top segment of companies exiting through IPOs, the answer seems to be negative. We find a mean IRR of $404 \%$ (median $162 \%$ ) in the US and a mean IRR of 1,370 \% (median 159\%) in Europe, and very similar numbers when we look at excess returns relative to the respective MSCI segments. So while the mean IPO returns are actually higher in Europe than in the US, and the medians indistinguishable (slightly higher in the US for absolute returns and higher in Europe for excess returns), none of these

\footnotetext{
${ }^{21}$ We searched Venture Economics but also a variety of other sources, including the Dealogic database on equity issuance, Lexis-Nexis and Factiva, national stock exchanges, and finally in a few cases communications from researchers monitoring IPO activity in Europe. We thank in particular Peter Roosenboom and Wolfgang Aussenegg for their help.

Our resampling strategy is so successful because a large number of European companies with successful exits had to be excluded earlier as we could not calculate an intermediate IRR, but we can now determine the IRR over the full venture cycle by adding the observation of their exit valuations. The ensuing exit sample is derived from the same Venture Economics base sample employed before and shows no systematic difference to the earlier sample.

${ }^{22} \mathrm{~A}$ necessary caveat, however, is that we compare IRRs over the full venture cycle to IRRs that stop at an intermediate funding period.
} 
differences is statistically significant as we report in Table 6 .

A different picture emerges when we look at trade sales. Here, the Europeans underperform, with a mean IRR of $-12.4 \%$ (median -30.4\%). Adverse market conditions can only account for a fraction of this poor performance, since excess returns are still substantially negative with a mean of $-7.7 \%$ (median $-20.4 \%$ ). By contrast, in the US acquisitions are positive, with a mean IRR of $156 \%$ (median $-2.6 \%$ ) that, when stripping out the contemporaneous MSCI market returns, become unambiguously positive with a mean of $159 \%$ (median of $6.7 \%$ ). Our $t$-tests show that the difference in means is significant at the $5 \%$ level, but there is only a weakly significant difference in medians.

Overall, we find that companies with an IPO exit perform similarly in the US and in Europe, whereas trade sales show some evidence of a performance difference. For the residual and (in our sample) largest segment, we cannot make any direct comparison since performance is of course unobservable. This segment encompasses the wide spectrum of companies that are written off, that do never exit or exit by other means, such as buybacks or financial acquisitions. But it seems possible to conclude that the observed difference on the trade sale subsample appears insufficient to explain the performance gap that we document for the full sample, based on the following simple calculation: a performance difference in median excess returns of $9.4 \%$ (168\% in means) in this segment cannot account for a difference of $84 \%$ in median excess returns in the full sample ( $483 \%$ in means; see Table 2 for the comparison), given that there is no difference in the IPO segment. ${ }^{23}$ Thus, it is highly probable that in the bottom segment for which we cannot observe performance, European venture capital strongly underperforms its US counterpart. On the whole, our findings appear consistent with the notion that the underperformance in Europe is explained by much lower returns for poorly performing companies.

An important caveat is that we have no means to verify whether the three main exit routes (IPOs, trade sales, and others) occur in roughly comparable frequencies in Europe and in the United States. It is possible that European venture capital underperforms not because in any of the three performance segments companies do less well than their US counterparts, but because top and medium performers are significant less frequent than in the USA. In either case, we

\footnotetext{
${ }^{23}$ While this comparison mixes different IRR concepts, a possible bias would work against our argument since differences in IRRs across segments should grow as we expand the horizon.
} 
conclude that the performance difference is likely to occur at the bottom of the hierarchy. However, we cannot say whether this is due to a less discriminating project selection or whether monitoring and stopping decisions of troubled venture projects are less successful.

\section{Robustness and Endogeneity Concerns}

\subsection{Sample Selection Bias}

Selection bias is an important concern in any empirical study on venture capital performance, and various authors have considered the problem as nearly inevitable in a database such as Venture Economics where all reporting is voluntary, and where reports are incomplete; even in the US database many valuations are unreported. As Woodward and Hall (2003) put it, the "companies that do report valuations are not a random sample, they are a biased sample. Good news is reported more often than bad" (p. 4). Kaplan and Schoar (2005) and Cochrane (2005) express a similar conviction that selection bias would create an upwards bias on returns.

The sample selection problem can be decomposed into two parts. First, the self-selection bias arising from the voluntary nature of reports. This bias cannot be corrected since no control sample without such a bias exists. Second, the bias for exited projects that arises if performance metrics

are based only on companies with a successful exit and a reported exit valuation. Exit samples are generally a biased sample, as the performance hierarchy discussed in Section 5. implies. Cochrane (2005) and Woodward and Hall (2003) present proposals to remedy for the bias for exited projects by applying Heckman corrections, based on imputed sample means that they obtain by using the best available (but still incomplete) reporting on the final exit routes of portfolio companies. Their methods cannot fully correct for sample selection bias, however, and we cannot replicate their procedures for lack of exit observations in the European sample.

Our return measure that spans only up to the last financing round and does not include the exit stage should be less exposed to the bias for exited projects for the following reason: poor performers that are written off or that have no recorded exit will not be included in a sample where performance is determined until exit, but they should be included in our sample (unless there was only a single financing round). While we do not want to put too much weight on this 
argument it is, in our view, an important theoretical advantage of our return measure.

We certainly concede that a self-selection bias produced by voluntarily reported valuations remains. Our primary argument with respect to this bias is that any bias present in our sample should work against our main result of a performance gap between the US and Europe. Since voluntary reporting to Venture Economics is much less complete in Europe than in the US, it should be easier for European funds than for US funds to report selectively (presumably there is less peer pressure to disclose transactions). As noted, voluntary selective reporting should typically translate into an upward bias. Thus, the upwards bias should be worse in Europe than in the US. Also, European deal reporting should be subject to less scrutiny from comparisons with other reporting sources, such as limited partners.

Finally, the aggregate return numbers for Europe imply very poor realized returns over the sample period, in absolute terms and relative to a variety of performance benchmarks, that make any large-scale upwards bias in returns unlikely.

\subsection{Endogeneity Problems}

An important concern is the possible endogeneity of the contracting-related variables in our regressions. For example, it could be argued that a highly significant variable such as AVG DURATION is determined by unobservable characteristics that influence both company performance and contracting choices since the contracting parties knew from the outset.

Reverse Causality. To a large extent, we should be able to address this concern by testing for the presence of reverse causality. Namely, if contracting choices are driven by unobserved characteristics that also determine performance, then regressing performance in early financing rounds on contracting conditions in subsequent rounds should show a significant relationship, assuming that returns are persistent over the sample horizon. The staged nature of venture funding provides a good opportunity to check for reverse causality, since the observation period in many cases encompasses more than two valuation observations so that we can construct dependent and independent variables over successive time periods. We proceed as follows. For all firms for which we have at least three valuations (119 US firms and 22 European firms), we compute an internal rate of return for financing round between the first and the second valuation (IRR1) 
and an internal rate of return for financing rounds between the second and the last valuation (IRR2). From these two internal rates of returns, we construct LOG EXC1 and LOG EXC2 and we also construct lifetime-information variables for the two periods in the same way as described in Section 4.1.. Running OLS regressions with LOG EXC1 as the explained variable and lifetimeinformation variables as explanatory variable for the full sample, we do not find any evidence of reverse causality: the coefficient for the AVG DURATION variable for the second period is insignificant, and the same is true for other contracting-related variables reported in Table 4 . The only exception is subsequent funding, since we do find a weakly significant positive relationship between performance in the first period and AVG AMOUNT in the second period. This relation-

ship, however, is expected and expresses only that VCs are reactive to good performance early on. Interestingly, we find such a reactive relationship only in the US, not in Europe.

Instrumental Variables Tests. Another standard method that we apply is to define instrumental variables for the variables possibly affected by endogeneity problems. For each of the contracting-related variables AVG AMOUNT, AVG SYNDICATE SIZE and AVG DURATION, as well as for the corresponding variables covering the first round (AMOUNT STAGE 1, SYNDICATE SIZE STAGE 1, and DURATION STAGE 1, we define as instruments the average values that we find for these variables over the entire US sample contained in Venture Economics. We then fit these instruments successively in an instrumental variables regression with the appropriate error correction. We find that the variables AVG DURATION, AVG AMOUNT and DURATION STAGE 1 remain significant in the full sample, but not in the European sample. Thus, overall our instrumental variables regressions seem to confirm that our results are not fundamentally driven by endogeneity.

\subsection{Return Benchmark}

We verified that our results on the performance gap are not driven by the choice of the respective benchmark indices, the MSCI US and MSCI Europe, respectively. While these are arguably the best available international equity market benchmarks, they report the returns on mature public equity markets whereas venture investments concern highly illiquid stakes in small technology firms. A better suited benchmark would be the segment of public equity markets that is closest 
to the sample of firm under consideration, i.e. a market index for small technology firms. The difficulty is that a convincing benchmark for European technology firms, even on a country level, is not available. We therefore benchmarked both the US and the European sample against the NASDAQ Composite index, and recalculated the LOG EXC variable. The findings are almost unchanged, both in the univariate comparison of the performance gap as in the regression analysis. In fact, as inspection of Table 3 shows, the impact of the benchmarking index is negligible compared to the level and risk in the LOG IRR variable.

\section{Conclusion}

Until very recently, research on venture capital has exclusively focused on the United States, and quite naturally so since this industry was hardly existent in other parts of the world. The bull market for high-tech firms in the late 1990s has created markets for venture capital elsewhere. This paper presents a comparative study of the performance of the VC industry in Europe and in the United States over the 1997-2003 period. Performance is measured by the internal rate of return of each VC-backed company between the first and the last financing round. Unlike earlier studies that have either calculated returns up to the exit stage, or used aggregate fund level performance that again includes only exited projects, this measure for VC performance systematically including projects that are write-offs or have no recorded exit. Moreover, the remaining (and important) sample selection bias that we cannot address should actually magnify the effect of our main result.

We show that the US venture capital industry strongly outperform their European peers. When trying to identify determinants of this performance gap, we find that contracting-related determinants play a crucial role: 1) US venture capitalists show a positive relationship between total funding and performance while the reverse is true for Europeans. One reason appears to be that US VCs react with an increased funding flow upon good early performance, in contrast to Europeans; 2) US VCs use instruments of control and contingent funding efficiently, since performance reacts positively to shorter funding intervals in the US, while the opposite is true in Europe; 3) US-based venture investors use syndication more effectively, as their syndicates grow over time, while their European counterparts do not. Moreover, US VCs include more specialized 
VCs and more corporate investors. Overall, there is evidence that US venture capitalists are more sophisticated than their European counterparts (in the sense that their behavior is more aligned with theoretical predictions) and that this contributes to the explanation of the difference in performance.

We also investigate possible reverse causality and define instruments to address endogeneity problems; these tests show that our results are unlikely to be driven by endogeneity.

When looking at other potential determinants of the performance gap we find no evidence that the performance gap can be attributed to the difference in legal origin between Common Law and Civil Law countries, to stock market capitalization, or to the tax environment for venture financing. Surprisingly, we do not find evidence that European companies that include US-based venture funds among their financiers perform any better than companies that rely exclusively on European homegrown funds. Thus, it seems that the larger expertise and more sophisticated approach to contracting of US VCs that is documented in a number of earlier and contemporaneous studies is not easily leveraged into other markets or successfully exported abroad. Disentangling the origins of this difficulty further is an important question for future research. 


\section{References}

[1] Admati, A. And P. Pfleiderer (1994), "Robust Financial Contracting and the Role of Venture Capitalists," Journal of Finance 49, pp. 371-402.

[2] Aghion, P. And P. Bolton (1992), "An Incomplete Contracts Approach to Financial Contracting," Review of Economic Studies 59, pp. 473-494

[3] Bascha, A. And U. Walz (2001) "Convertible Securities and Optimal Exit Decisions in Venture Capital Finance," Journal of Corporate Finance 7, pp. 285-306.

[4] Barry, C., C. Muscarella, J. Perry and M. Vetsuypens (1990), "The Role of Venture Capital in the Creation of Public Companies: Evidence from the Going Public Process," Journal of Financial Economics 27, pp. 447-471.

[5] Bergemann, D. And U. Hege (2003), "The Value of Benchmarking," in: J.A. McCahery, L. Renneboog (eds.) Venture Capital Contracting and the Valuation of High Tech Firms, Oxford: Oxford University Press, pp. 83-107.

[6] Berk, J., R. Green, And V. Naik (2004), "Valuation and Return Dynamics of New Ventures," Review of Financial Studies 17, pp. 1-35.

[7] Black, B. And R. Gilson (1998), "Venture Capital and the Structure of Capital Markets: Banks versus Stock Markets," Journal of Financial Economics 47, pp. 243-277.

[8] Bottazzi, L., M. Da Rin and T. Hellmann (2004), "Active Financial Intermediation: Evidence of the Role of Organizational Specialization and Human Capital," RICAFE WP 12, http://ww.lse.ac.uk/ricafe.

[9] Bottazzi, L., M. Da Rin and T. Hellmann (2005), "What Role of Legal Systems in Financial Intermediation? Theory and Evidence," RICAFE Working Paper 22, http://ww.lse.ac.uk/ricafe.

[10] Bruining, H., Verwaal, M. Wright, A. Lockett and S. Manigart (2005), "Firm size effects on syndication participation in European venture capital syndicates," Entrepreneurship Theory and Practice, forthcoming.

[11] Casamatta, C. (2003) "Financing and Advising. Optimal Financial Contracts with Venture Capitalists," Journal of Finance 58, pp. 2059-2085.

[12] Casamatta, C. and C. Haritchabalet (2007), "Experience, Screening and Syndication in Venture Capital Investments," forthcoming, Journal of Financial Intermediation.

[13] Cestone, G., J. Lerner and L. White (2005), "The Design of Syndicates in Venture Capital," Working Paper, University of Lausanne.

[14] Cochrane, J. (2005), "The Risk and Return of Venture Capital," Journal of Financial Economics 75, pp. 3-52. 
[15] Cornelli, F. and O. Yosha (2003), "Stage Financing and the Role of Convertible Debt," Review of Economic Studies 70, pp. 1-32.

[16] Cumming, D., G. Fleming and A. Schwienbacher (2006), "Legality and Venture Capital Exits," Journal of Corporate Finance 12, pp. 214-245.

[17] Cumming, D. and U. Walz (2004) "Valuation and Disclosure of Private Equity Investments Around the World," University of Frankfurt, CFS WP No. 2004/05.

[18] Cumming, D., D. Schmidt and U. Walz (2004) "Legality and Venture Governance around the World," University of Frankfurt, CFS WP No. 2004/17.

[19] Cuny, C. J. and E. Talmor (2003) "The Staging of Venture Capital Financing: Milestones vs. Rounds," Working Paper, Texas A\&M University and London Business School.

[20] Da Rin, M. G. Nicodano and A. Sembenelli (2006) "Public Policy and the Creation of Active Venture Capital Markets," Journal of Public Economics 80 (8-9), pp. 1699-1723.

[21] Elitzur, R. And A. Gavious (2003) "A Multi-Period Theoretic Model of Venture Capitalists and Entrepreneurs," European Journal of Operational Research 144, pp. 440-453.

[22] EvCa (European Venture Capital Association) (2003) "Benchmarking European Tax and Legal Environments," EVCA Benchmark Paper, Zaventem, http://www.evca.com/images/attachments/tmpl_9_art_60_att_321.pdf.

[23] Gilson, R. And D. Schizer (2002), "Understanding Venture Capital Structure: A Tax Explanation for Convertible Preferred Stock," Columbia Law School WP No. 230.

[24] Gompers, P. (1995), "Optimal Investment, Monitoring, and the Staging of Venture Capital," Journal of Finance 50, pp. 1461-1489.

[25] Gompers, P. And J. Lerner (1999), The Venture Capital Cycle, Cambridge: MIT Press.

[26] Gottschalg, O. And L. Phallipou (2007), "Performance of Private Equity Funds: Another Puzzle?" Review of Financial Studies, forthcoming.

[27] Hellmann, T. (1998), "The Allocation of Control Rights in Venture Capital Contracts," Rand Journal of Economics 29 (1), pp. 57-76.

[28] Hellmann, T. (2002), "A Theory of Strategic Venture Investing," Journal of Financial Economics 64, pp. 285-314.

[29] Hochberg, Y., A. Luungqvist and Y. Lu (2007), "Whom You Know Matters: Venture Capital Networks and Investment Performance," Journal of Finance 61 (1), pp. 251-302.

[30] Jones And Rhodes-Kropf (2004) "The Price of Diversifiable Risk in Venture Capital and Private Equity," mimeo, Columbia University Graduate School of Business, http://www0.gsb.columbia.edu/faculty/mrhodeskropf/papers/VCRiskReturnRFS.pdf 
[31] Kahneman, D. And A. Tversky (1979), "Prospect Theory: An Analysis of Decisions under Risk," Econometrica 47, pp. 313-327.

[32] Kaplan, S. and A. Schoar (2005), "Private Equity Performance: Returns, Persistence, and Capital Flows," Journal of Finance 60, pp. 1791-1823.

[33] Kaplan, S. and P. Strömberg (2003), "Financial Contracting Theory Meets the Real World: An Empirical Analysis of Venture Capital Contracts," Review of Economic Studies 70, pp. 281-315.

[34] Kaplan, S., F. Martel and P. Strömberg (2003), "How Do Legal Differences and Learning Affect Financial Contracts?" Journal of Financial Intermediation, forthcoming..

[35] Lakonishok, J., A. Shleifer, R. Thaler and R. Vishny (1991), "Window Dressing by Pension Fund Managers," American Economic Review 81, pp. 227-231.

[36] La Porta, R., F. Lopez-de-Silanes, A. Shleifer, and R. Vishny (1997), "Legal Determinants of External Finance," Journal of Finance 52, pp. 1131-1150.

[37] La Porta, R., F. Lopez-de-Silanes, A. Shleifer, and R. Vishny (1998), "Law and Finance," Journal of Political Economy 106, pp. 1113-55.

[38] Lerner, J. (1999) "The Government as Venture Capitalist: An Empirical Analysis of the SBIR Program," Journal of Business 72, pp. 285-318.

[39] Lerner, J. And A. Schoar (2004), "Private Equity in the Developing World: The Determinants of Transaction Structures," NBER WP No. 10348.

[40] Luungqvist, A. And M. Richardson (2003), "The Cash Flow, Return and Risk Characteristics of Private Equity," http://papers.ssrn.com/sol3/papers.cfm?abstract_id=369600

[41] Manigart, S., K. DeWaele, M. Wright, K. Robbie, P. Desbrieres, H.J. Sapienza, AND A. BEEKMAN (2002), "The determinants of the required returns in venture capital investments: a five-country study," Journal of Business Venturing 17, pp. 291-312.

[42] Mayer, C., K. Schoors, And Y. Yafeh (2005), "Sources of funds and investment activities of venture capital funds: evidence from Germany, Israel, Japan and the UK." Journal of Corporate Finance 11, pp. 586-608.

[43] Neher, D. (1999) "Stage Financing: An Agency Perspective," Review of Economic Studies 66, pp. 255-274.

[44] Rajan, R.G. (1992), "Insiders and Outsiders: The choice between informed and arm's length debt," Journal of Finance 47, pp. 1367-1400.

[45] Rajan, R.G. And L. Zingales (2003), "The Great Reversals: The Politics of Financial Development in the Twentieth Century," Journal of Financial Economics 69, pp. 5-50. 
[46] Repullo, R. And Suarez, J. (2004), "Venture Capital Finance: A Security Design Approach,"Review of Finance 8, pp. 75-108.

[47] Riyanto, Y. and A. Schwienbacher (2006), "On the Strategic Use of Corporate Venture Financing for Securing Demand," Journal of Banking and Finance 31 (3), pp. 679-702.

[48] Schwienbacher, A. (2004), "An Empirical Analysis of Venture Capital Exits in Europe and in the United States," mimeo, University of Amsterdam.

[49] Sahlman, W. (1990), "The Structure and Governance of Venture-Capital Organizations," Journal of Financial Economics 27, pp. 473-521.

[50] Sapienza, H., S. Manigart, and W. Vermeir (1996), "Venture capital governance and value-added in four countries," Journal of Business Venturing 11, pp. 439-469.

[51] Schmidt, K. (2003), "Convertible Securities and Venture Capital Finance," Journal of Finance 58, pp. 1139-65

[52] Schmidt, D. and M. Wahrenburg (2003), "Contractual Relations between EuropeanVC Funds and Investors: The Impact of Reputation and Bargaining Power on Contractual Design," RICAFE WP 12, http://ww.lse.ac.uk/ricafe.

[53] Woodward, S. and R. Hall (2003), "Benchmarking The Returns to Venture," NBER WP 10202, http://www.nber.org/papers/w10202. 


\section{Appendix}

\begin{tabular}{|l|c|c|c|c|c|c|}
\hline \hline & Obs. & Mean & Std.Dev. & Median & Min. & Max. \\
\hline TMT (dummy) & 379 & 0.483 & 0.500 & 0 & 0 & 1 \\
\hline Corporate Investor (dummy) & 376 & 0.293 & 0.456 & 0 & 0 & 1 \\
\hline Age (years) & 319 & 2.145 & 3.181 & 1.071 & 0 & 22 \\
\hline Total Duration (years) & 379 & 1.807 & 1.041 & 1.666 & 0.25 & 5.306 \\
\hline Total Stages & 379 & 3.398 & 1.424 & 3 & 2 & 11 \\
\hline Avg Duration (years) & 379 & 0.851 & 0.485 & 0.737 & 0.065 & 3.145 \\
\hline Avg Syndicate Size & 379 & 3.336 & 1.914 & 3 & 1 & 13.33 \\
\hline Avg Amount (\$ Mill.) & 377 & 10.776 & 11.345 & 7.45 & 0.018 & 83.66 \\
\hline Avg Continuity & 379 & 0.235 & 0.186 & 0.203 & 0 & 0.8 \\
\hline Early Continuity (dummy) & 379 & 0.402 & 0.375 & 0.333 & 0 & 1 \\
\hline Duration Stage 1(years) & 379 & 0.822 & 0.548 & 0.668 & 0.06 & 3.145 \\
\hline Syndicate Size Stage 1 & 379 & 2.493 & 1.721 & 2 & 1 & 18 \\
\hline Amount Stage 1 (\$ Mill.) & 377 & 5.706 & 7.914 & 3.0 & 0 & 79.57 \\
\hline \multicolumn{1}{|c|}{ - relative to avg round investment } & 377 & 0.700 & 0.632 & 0.523 & 0 & 3.571 \\
\hline - as \% of initial firm value & 231 & 38.02 & 21.35 & 35.46 & 0.017 & 100 \\
\hline Bubble start & 379 & 0.485 & 0.500 & 0 & 0 & 1 \\
\hline Bubble end & 379 & 0.169 & 0.375 & 0 & 0 & 1 \\
\hline \hline
\end{tabular}

Table 1: Sample Characteristics. This table records sample means and related statistics for the combined sample of US and European venture-backed companies. The table includes all companies in the sample with a first financing round in 1996 or later, if the companies were seed or early stage in at least one round, and had at least one successive valuation recorded. Age is the difference between the first recorded financing round and the company's founding date. Total Duration is the time elapsed between the first financing round and the last round for which a valuation is recorded. Total Stages is the total number of financing rounds, and Average Duration is Total Duration / Total Stages. Total Investors reports the number of investors participating in at least one financing round. Total Investment Amount is the combined sum of financing in all rounds. Amount per Investor is Total Investment amount / Total Number of Investors. Funds Present in All Stages (Dummy) is equal to one if at least one investor provided funds in all rounds, and zero otherwise. Funds Present in All Stages (Number) is the number of investors that provided funds in all rounds. Average continuity is the average percentage of prevous investors providing funds in the next stage. Early continuity is a dummy that is equal to one if at least one investor participated in the first and second round. Initial duratin is the duratin of the first stage. Number Investors First Round the number participating in the first round. Initial Q is the ratio of valuation and investment in the first round, provided both numbers are reported. Started prior to 1998 is a dummy equal to one if the first stage commenced prior to September 1998. Final Value 1998 - March 2000 is a dummy equal to one if the last stage with a round valuation falls onto these 19 months commonly associated with the internet bubble. Sector TMT is a dummy equal to one if the company falls into internet or telecommunications, media. 


\begin{tabular}{|l|c|c|c|c|}
\hline \hline & Mean Europe & Mean USA & Difference & $P$-value \\
\hline TMT & 0.486 & 0.480 & 0.489 & 0.916 \\
\hline Corporate Investor (dummy) & 0.181 & 0.361 & $-0.178^{* * * *}$ & 0.001 \\
\hline Age (years) & 2.455 & 1.965 & 0.006 & 0.187 \\
\hline Total Duration (years) & 1.878 & 1.692 & 0.186 & $0.0893^{*}$ \\
\hline Total stages & 3.328 & 3.442 & 0.114 & 0.4518 \\
\hline Avg Duration (years) & 0.860 & 0.844 & 0.16 & 0.753 \\
\hline Avg Syndicate Size & 2.828 & 3.656 & $-0.828^{* * * *}$ & 0.000 \\
\hline Total Investment Amount (\$ Mill.) & 27.332 & 49.218 & $-21.882^{* * * *}$ & 0.000 \\
\hline Avg Amount (\$ Mill.) & 7.688 & 12.684 & $-4.99^{* * * *}$ & 0.000 \\
\hline Avg Continuity & 0.269 & 0.212 & $0.057^{* * *}$ & 0.003 \\
\hline Early Continuity (Dummy) & 0.444 & 0.376 & $0.068^{*}$ & 0.086 \\
\hline Duration Stage 1 (years) & 0.844 & 0.809 & 0.035 & 0.542 \\
\hline Syndicate Size Stage 1 & 2.369 & 2.570 & -0.201 & 0.269 \\
\hline Amount Stage 1 (\$ Mill.) & 5.45 & 5.86 & -0.41 & 0.682 \\
\hline \multicolumn{1}{|c|}{ - relative to avg round investment } & 0.870 & 0.595 & $0.275^{* * * *}$ & 0.000 \\
\hline - as \% of initial firm value & 18.7 & 15.6 & 3.16 & 0.844 \\
\hline Bubble Start & 0.445 & 0.510 & -0.065 & 0.215 \\
\hline Bubble End & 0.055 & 0.240 & $-0.185^{* * * *}$ & 0.000 \\
\hline \hline Number of Observations & 146 & 233 & & \\
\hline \hline
\end{tabular}

Table 2: Tests for Differences in Means for Sample Characteristics. This table tests for differences in sample means between US and European venture-backed companies. The table includes all companies in the sample with a first financing round in 1996 or later, if the companies were seed or early stage in at least one round, and had at least one successive valuation recorded. All variables are as defined in Table 1. The number of observations is as recorded in the last row, except for Funds in All Stages (2 ob. missing), Age (62 obs. missing), and Initial Q (149 obs. missing). Two-sided $t$-test for difference in mean (equal variance in both samples), $H_{0}$ : Difference is equal to zero. Levels of significance: ${ }^{*}=10 \%,{ }^{* *}=5 \%,{ }^{* * *}=1 \%,{ }^{* * * *}=0.1 \%$. 


\begin{tabular}{|l|c|c|c|c|c|c|}
\hline \hline \multicolumn{1}{|c|}{ Panel A: } & \multicolumn{6}{c|}{ Full Sample } \\
\hline & Number of Obs. & Mean & Std.Deviation & Median & Min. & Max. \\
\hline IRR & 379 & 1.958 & 5.850 & 0.2139 & -0.9920 & 35.670 \\
\hline Excess Return & 379 & 1.964 & 5.810 & 0.2777 & -0.9644 & 35.541 \\
\hline Log IRR & 379 & 0.1595 & 1.445 & 0.1939 & -4.8364 & 3.602 \\
\hline Log Excess Return & 379 & 0.1940 & 1.452 & 0.2624 & -4.8364 & 4.937 \\
\hline \hline
\end{tabular}

\begin{tabular}{|c|c|c|c|c|c|c|}
\hline Panel B: & \multicolumn{6}{|c|}{ Europe and USA } \\
\hline & \multicolumn{2}{|c|}{ Europe } & \multicolumn{2}{|c|}{ US } & \multicolumn{2}{|c|}{ Tests } \\
\hline Number of Obs. & \multicolumn{2}{|c|}{146} & \multicolumn{2}{|c|}{233} & Diff. in means & Diff. in medians \\
\hline & Mean & Median & Mean & Median & $P$-value & $P$-value \\
\hline IRR & 0.625 & -0.2519 & 2.7936 & 0.6137 & 0.000 & 0.000 \\
\hline Excess Return & 0.665 & -0.2075 & 2.7776 & 0.6242 & 0.000 & 0.000 \\
\hline Log IRR & -0.601 & -0.2903 & 0.6360 & 0.4785 & 0.000 & 0.000 \\
\hline Log Excess Return & -0.544 & -0.3099 & 0.6565 & 0.4723 & 0.000 & 0.000 \\
\hline
\end{tabular}

\begin{tabular}{|c|c|c|c|c|c|c|}
\hline Panel C: & \multicolumn{6}{|c|}{ Europe } \\
\hline & \multicolumn{2}{|c|}{ with US VC } & \multicolumn{2}{|c|}{ without US VC } & \multicolumn{2}{|c|}{ Tests } \\
\hline \multirow[t]{2}{*}{ Number of Obs. } & \multicolumn{2}{|c|}{96} & \multicolumn{2}{|c|}{50} & Diff. in means & Diff. in medians \\
\hline & Mean & Median & Mean & Median & $P$-value & $P$-value \\
\hline IRR & 0.5940 & -0.1894 & 0.6832 & -0.3941 & 0.45 & 0.38 \\
\hline Excess Return & 0.6250 & -0.1381 & -0.6008 & -0.4083 & 0.44 & 0.38 \\
\hline Log IRR & -0.4892 & -0.2103 & -0.8151 & -0.5011 & 0.86 & 0.38 \\
\hline Log Excess Return & -0.4359 & -0.1565 & -0.7521 & 0.4908 & 0.86 & 0.38 \\
\hline
\end{tabular}

\begin{tabular}{|l|c|c|c|c|c|c|}
\hline \hline \multicolumn{1}{|c|}{ Panel D: } & \multicolumn{5}{c|}{ Europe } \\
\hline & \multicolumn{4}{|c|}{ Common Law Countries } & \multicolumn{1}{c|}{ Civil Law Countries } & \multicolumn{2}{c|}{ Tests } \\
\hline Number of Obs. & \multicolumn{2}{|c|}{74} & \multicolumn{2}{c|}{72} & Diff. in means & Diff. in medians \\
\hline & Mean & Median & Mean & Median & $P$-value & $P$-value \\
\hline IRR & 0.4350 & -0.4523 & 1.7069 & -0.1272 & 0.29 & 0.069 \\
\hline Excess Return & 0.4828 & -0.3984 & 1.7380 & -0.1361 & 0.30 & 0.136 \\
\hline Log IRR & -1.2708 & -0.6026 & -0.3355 & -0.1361 & 0.027 & 0.069 \\
\hline Log Excess Return & -1.211 & -0.5461 & -0.2934 & -0.1145 & 0.027 & 0.247 \\
\hline \hline
\end{tabular}

Table 3: Summary Statistics for Returns. This table records sample means, medians and related statistics for the full sample (Panel A) of 233 US and 146 European companies. The table includes all companies that obtained a first financing round in 1997 or later, are genuine venture-backed companies (seed or early stage funding in at least one round or less than 3 years old), and had at least one successive valuation recorded. Data are winsorized at the 1 Panel B reports means and medians for the subsamples in Europe and the US. The tests are two-sided $t$-tests for differences in sample means (unequal variances according to Satterthwaite's method) and a Wilcoxon signed rank test for medians. $H_{0}$ : Difference is equal to zero. IRR: internal rate of returns, between first valution date 0 and last valuation date $T$, calculated as rate $r$ such that $\frac{V_{T}}{(1+r)^{T}}-\sum_{t} \frac{I_{t}}{(1+r)^{t}}-V_{0}=0$, where $V_{T}$ is the final valuation, $V_{0}$ the initial valuation, and $I_{t}$ the investment amount in period $0<t \leq T$.Log IRR: IRR in logs. Excess Return (Log Excess Return): IRR - annualized return on MSCI over the same period (in logs). Panels C compares fo the European subsample the IRRs for companies with or without at least one US-based VC firm participating in at least one round. Panel $\mathrm{C}$ distinguishes between common law countries (UK and Ireland) and other countries in the European subsample. Levels of significance: ${ }^{*}=10 \%,{ }^{* *}=5 \%,{ }^{* * *}=1 \%,{ }^{* * * *}=0.1 \%$. 
Full sample

\begin{tabular}{|c|c|c|c|c|c|}
\hline & (1) & $(2)$ & $(3)$ & (4) & $(5)$ \\
\hline EU Dummy & $\begin{array}{c}-1.0718^{* * * *} \\
(-7.76)\end{array}$ & $\begin{array}{c}-1.2038^{* * * *} \\
(-5.26)\end{array}$ & $\begin{array}{c}-1.193^{* * *} \\
(-2.80)\end{array}$ & $\begin{array}{c}-1.2057^{* * *} \\
(-2.94)\end{array}$ & $\begin{array}{c}-1.201^{* * *} \\
(-2.87)\end{array}$ \\
\hline Common Law & & $\begin{array}{c}-0.0933 \\
(-0.39)\end{array}$ & $\begin{array}{c}-0.0195 \\
(-0.08)\end{array}$ & & \\
\hline Market Cap./GDP & & & & $\begin{array}{l}-0.0746 \\
(-0.34)\end{array}$ & \\
\hline Tax and Legal Score (EVCA) & & & & & $\begin{array}{c}0.0484 \\
(0.19)\end{array}$ \\
\hline Bubble Start & & $\begin{array}{c}0.341^{* * *} \\
(2.63)\end{array}$ & $\begin{array}{c}0.279^{* *} \\
(2.14)\end{array}$ & $\begin{array}{c}0.276^{* *} \\
(2.12)\end{array}$ & $\begin{array}{c}0.276^{* *} \\
(2.12)\end{array}$ \\
\hline Bubble Start $\times$ EU Dummy & & $\begin{array}{l}0.381 \\
(1.40)\end{array}$ & $\begin{array}{l}0.212 \\
(0.82)\end{array}$ & $\begin{array}{l}0.196 \\
(0.75)\end{array}$ & $\begin{array}{l}0.197 \\
(0.75)\end{array}$ \\
\hline TMT & & $\begin{array}{c}0.2444^{*} \\
(1.85)\end{array}$ & $\begin{array}{l}0.215^{*} \\
(1.65)\end{array}$ & $\begin{array}{l}0.212^{*} \\
(1.65)\end{array}$ & $\begin{array}{l}0.212^{*} \\
(1.65)\end{array}$ \\
\hline TMT $\times$ EU Dummy & & $\begin{array}{l}-0.140 \\
(-0.52)\end{array}$ & $\begin{array}{l}0.097 \\
(0.40)\end{array}$ & $\begin{array}{l}0.104 \\
(0.39)\end{array}$ & $\begin{array}{l}0.107 \\
(0.40)\end{array}$ \\
\hline Early Cont. & & & $\begin{array}{l}-0.133 \\
(-0.70)\end{array}$ & $\begin{array}{l}-0.133 \\
(-0.67)\end{array}$ & $\begin{array}{l}-0.133 \\
(-0.67)\end{array}$ \\
\hline Early Cont $\times$ EU Dummy & & & $\begin{array}{l}-0.121 \\
(-0.34)\end{array}$ & $\begin{array}{l}-0.104 \\
(-0.30)\end{array}$ & $\begin{array}{l}-0.110 \\
(-0.31)\end{array}$ \\
\hline Amount Stage 1 & & & $\begin{array}{c}-0.366^{* * *} \\
(-3.14)\end{array}$ & $\begin{array}{c}-0.3662^{* * *} \\
(-3.14)\end{array}$ & $\begin{array}{c}-0.3661^{* * *} \\
(-3.14)\end{array}$ \\
\hline Amount Stage $1 \times$ EU Dummy & & & $\begin{array}{l}-0.187 \\
(-0.99)\end{array}$ & $\begin{array}{l}-0.185 \\
(-0.97)\end{array}$ & $\begin{array}{l}-0.187 \\
(-0.98)\end{array}$ \\
\hline Syndicate Size Stage 1 & & & $\begin{array}{l}-0.122 \\
(-0.44)\end{array}$ & $\begin{array}{l}-0.122 \\
(-0.44)\end{array}$ & $\begin{array}{l}-0.122 \\
(-0.44)\end{array}$ \\
\hline Syndicate Size Stage $1 \times$ EU Dummy & & & $\begin{array}{c}-0.0242 \\
(-0.33)\end{array}$ & $\begin{array}{c}-0.0263 \\
(-0.36)\end{array}$ & $\begin{array}{c}-0.0263 \\
(-0.35)\end{array}$ \\
\hline Duration Stage 1 & & & $\begin{array}{c}-0.0006^{* *} \\
(-2.09)\end{array}$ & $\begin{array}{c}-0.0006^{* *} \\
(-2.09)\end{array}$ & $\begin{array}{c}-0.0006^{* *} \\
(-2.09)\end{array}$ \\
\hline Duration Stage $1 \times$ EU Dummy & & & $\begin{array}{c}0.0013^{* * *} \\
(2.94)\end{array}$ & $\begin{array}{c}0.0013^{* * *} \\
(2.92)\end{array}$ & $\begin{array}{c}0.0013^{* * *} \\
(2.95)\end{array}$ \\
\hline Constant & $\begin{array}{c}0.6007^{* * * *} \\
(9.09)\end{array}$ & $\begin{array}{r}0.4049 \\
(1.59)\end{array}$ & $\begin{array}{c}0.8674^{* * *} \\
(2.82)\end{array}$ & $\begin{array}{c}0.9392^{* * *} \\
(2.92)\end{array}$ & $\begin{array}{c}0.7801^{* *} \\
(1.99)\end{array}$ \\
\hline$R^{2}$ & 0.1619 & 0.2141 & 0.2917 & 0.2920 & 0.2918 \\
\hline $\mathrm{F}$ & $15.93^{* * * *}$ & $13.31^{* * * *}$ & $9.48^{* * * *}$ & $9.45^{* * * *}$ & $9.46^{* * * *}$ \\
\hline Observations & 371 & 371 & 369 & 369 & 369 \\
\hline
\end{tabular}

Table 4a: Impact of Contracting Conditions in the Initial Round. OLS Regression (Log Excess Return as Dependent Variable). Robust regressions for the full sample of US and European companies with first financing round in 1997 or later, genuine venture capital (seed or early stage funding in at least one round or less than 3 years old), and at least one successive reported valuation. EU Dummy $=1$ if company based in the EU-15 countries, and EU Dummy $=0$ for US-based companies. Common Law $=1$ if the country has a Common Law system (US, UK, and Ireland) and equal to 0 otherwise (all other countries). Stock Market Cap./GDP is the 1997 ratio of aggregate stock market capitalization to GDP. EVCA tax and legal score is an index documented in EVCA (2003) and comprised between 1 (favorable) and 3 (unfavorable); the US score is based on the authors' calculations. All other variables are explained in Table 1. Sample is winsorized at 1\%. Heteroskedasticity-consistent (White) $t$-statistics in brackets. Levels of significance: ${ }^{*}=10 \%,{ }^{* *}=5 \%,{ }^{* * *}=1 \%,{ }^{* * * *}=0.1 \%$. 
Full sample

\begin{tabular}{|c|c|}
\hline & $(3)$ \\
\hline EU Dummy & $\begin{array}{c}-1.955^{* * * *} \\
(-3.91)\end{array}$ \\
\hline Common Law & $\begin{array}{l}0.126 \\
(0.49)\end{array}$ \\
\hline Bubble Start & $\begin{array}{l}0.221^{*} \\
(1.75)\end{array}$ \\
\hline Bubble Start $\times$ EU Dummy & $\begin{array}{c}0.549^{* *} \\
(2.11)\end{array}$ \\
\hline TMT & $\begin{array}{c}0.1609 \\
(1.26)\end{array}$ \\
\hline TMT $\times$ EU Dummy & $\begin{array}{c}0.1613 \\
(0.61)\end{array}$ \\
\hline Corp. Investor & $\begin{array}{c}0.0632 \\
(0.43)\end{array}$ \\
\hline Corp. Investor $\times \mathrm{EU}$ Dummy & $\begin{array}{c}0.756^{* * *} \\
(2.99)\end{array}$ \\
\hline Avg. Continuity & $\begin{array}{l}-0.673^{*} \\
(-1.78)\end{array}$ \\
\hline Avg. Continuity $\times$ EU Dummy & $\begin{array}{l}-0.146 \\
(-0.22)\end{array}$ \\
\hline Avg. Amount & $\begin{array}{c}0.0187^{* * *} \\
\quad(3.04)\end{array}$ \\
\hline Avg. Amount $\times$ EU Dummy & $\begin{array}{c}-0.045^{* *} \\
(-2.32)\end{array}$ \\
\hline Avg. Duration & $\begin{array}{c}-0.450^{* * *} \\
(-3.12)\end{array}$ \\
\hline Avg. Duration $\times$ EU dummy & $\begin{array}{c}0.736^{* * * *} \\
(3.42)\end{array}$ \\
\hline Avg. Syndicate Size & $\begin{array}{l}-0.0358 \\
(-0.95)\end{array}$ \\
\hline Avg. Syndicate Size $\times$ EU Dummy & $\begin{array}{l}0.139^{*} \\
(1.69)\end{array}$ \\
\hline Constant & $\begin{array}{l}0.684^{*} \\
(1.88)\end{array}$ \\
\hline$R^{2}$ & 0.3119 \\
\hline $\mathrm{F}$ & $7.08^{* * * *}$ \\
\hline Observations & 366 \\
\hline
\end{tabular}

Table 4b: Impact of Contracting Conditions over All Rounds. OLS Regression with Log Excess Return as Dependent Variable. Robust regressions for the full sample of US and European companieswith a first financing round in 1997 or later and that are genuine venture-backed companies (seed or early stage funding in at least one round or less than 3 years old), and had at least one successive valuation recorded. EU Dummy $=1$ if the company is based in one of the EU-15 countries, and EU Dummy $=0$ if the company is in the US. All other variables are explained in Table 1 and Table 4a. The sample is winsorized by eliminating $1 \%$ of outliers. Heteroskedasticity-consistent (White) $t$-statistics in brackets. Levels of significance: ${ }^{*}=10 \%,{ }^{* *}=5 \%$, ${ }^{* * *}=1 \%,{ }^{* * * *}=0.1 \%$. 


\begin{tabular}{|c|c|c|c|}
\hline \multicolumn{4}{|c|}{ Europe } \\
\hline & (1) & $(2)$ & $(3)$ \\
\hline \multirow[t]{2}{*}{ Common Law } & -0.3025 & -0.1991 & -0.0679 \\
\hline & $(-1.15)$ & $(-0.77)$ & $(-0.24)$ \\
\hline \multirow[t]{2}{*}{ US VC } & -0.0018 & -0.0242 & 0.0683 \\
\hline & $(-0.06)$ & $(-0.08)$ & $(0.23)$ \\
\hline \multirow[t]{2}{*}{ Bubble Start } & 0.4553 & 0.170 & 0.4432 \\
\hline & $(1.41)$ & $(0.51)$ & $(1.27)$ \\
\hline \multirow[t]{2}{*}{ TMT } & 0.324 & $0.528^{*}$ & 0.5325 \\
\hline & $(1.13)$ & $(1.89)$ & $(1.87)$ \\
\hline \multirow[t]{2}{*}{ Corp. Investor } & & & $0.9152^{* * *}$ \\
\hline & & & $(4.03)$ \\
\hline \multirow[t]{2}{*}{ Early Cont. } & & -0.348 & \\
\hline & & $(-1.01)$ & \\
\hline \multirow[t]{2}{*}{ Amount Stage 1} & & $-0.718^{* * * *}$ & \\
\hline & & $(-3.60)$ & \\
\hline \multirow[t]{2}{*}{ Syndicate Size Stage 1} & & -0.1329 & \\
\hline & & $(-1.05)$ & \\
\hline \multirow[t]{2}{*}{ Duration Stage 1} & & $0.0007^{* *}$ & \\
\hline & & $(1.66)$ & \\
\hline \multirow[t]{2}{*}{ Avg. Continuity } & & & -1.179 \\
\hline & & & $(-1.41)$ \\
\hline \multirow[t]{2}{*}{ Avg. Amount } & & & -0.0172 \\
\hline & & & $(-0.87)$ \\
\hline \multirow[t]{2}{*}{ Avg. Duration } & & & $0.3942^{*}$ \\
\hline & & & $(1.96)$ \\
\hline \multirow[t]{2}{*}{ Avg. Syndicate Size } & & & 0.0228 \\
\hline & & & $(0.22)$ \\
\hline \multirow[t]{2}{*}{ Constant } & $-0.761^{* * *}$ & 0.1388 & $-1.1184^{* *}$ \\
\hline & $(-3.14)$ & $(0.30)$ & $(-2.37)$ \\
\hline$R^{2}$ & 0.0475 & 0.1803 & 0.1811 \\
\hline $\mathrm{F}$ & 0.088 & $5.97^{* * * *}$ & $5.12^{* * * *}$ \\
\hline Observations & 143 & 141 & 138 \\
\hline
\end{tabular}

Table 5: OLS regression with log Excess Return as dependent variable. Robust regressions for European companies started in 1997 or later and are genuine venture-backed companies (seed or early stage funding in at least one round or less than 3 years old), and had at least one successive valuation recorded. All variables are explained in Table 1 . The sample is winsorized by eliminating $1 \%$ of outliers. Heteroskedasticity-consistent (White) $t$-statistics in brackets. Levels of significance: ${ }^{*}=10 \%,{ }^{* *}=5 \%,{ }^{* * *}=1 \%,{ }^{* * *}=0.1 \%$. 


\begin{tabular}{|c|c|c|c|c|}
\hline \hline Panel A: & \multicolumn{3}{|c|}{ Full Sample } \\
\hline & \multicolumn{2}{|c|}{ IPOs } & \multicolumn{2}{c|}{ Trade Sales } \\
\hline Number of obs. & \multicolumn{2}{|c|}{76} & \multicolumn{2}{c|}{51} \\
\hline & mean & median & mean & median \\
\hline IRR & 10.012 & 1.6072 & 0.9328 & -0.0882 \\
\hline Excess Return & 9.884 & 1.5169 & 0.9692 & 0.0056 \\
\hline Log IRR & 0.9206 & 0.9583 & -0.0292 & -0.0924 \\
\hline Log Excess Return & 0.8095 & 0.8289 & 0.0146 & 0.0059 \\
\hline
\end{tabular}

\begin{tabular}{|c|c|c|c|c|c|c|}
\hline \hline Panel B: & \multicolumn{5}{c|}{ IPOs } \\
\hline & \multicolumn{2}{|c|}{ Europe } & \multicolumn{2}{c|}{ United States } & \multicolumn{2}{c|}{ Tests } \\
\hline Number of obs. & \multicolumn{2}{|c|}{47} & \multicolumn{2}{c|}{29} & Diff. in means & Diff. in medians \\
\hline & mean & median & mean & median & $P$-value & $P$-value \\
\hline IRR & 13.692 & 1.5906 & 4.047 & 1.6261 & 0.195 & 0.813 \\
\hline Excess Return & 13.565 & 1.5169 & 3.917 & 1.472 & 0.195 & 0.479 \\
\hline Log IRR & 0.8873 & 0.9519 & 0.9743 & 0.9655 & 0.206 & 0.813 \\
\hline Log Excess Return & 0.7798 & 0.8351 & 0.8576 & 0.823 & 0.187 & 0.813 \\
\hline
\end{tabular}

\begin{tabular}{|c|c|c|c|c|c|c|}
\hline \hline Panel C: & \multicolumn{5}{|c|}{ Trade Sales } \\
\hline & \multicolumn{2}{|c|}{ Europe } & \multicolumn{2}{c|}{ United States } & \multicolumn{2}{c|}{ Tests } \\
\hline Number of obs. & \multicolumn{2}{|c|}{19} & \multicolumn{2}{|c|}{32} & Diff. in means & Diff. in medians \\
\hline & mean & median & mean & median & $P$-value & $P$-value \\
\hline IRR & -0.1241 & -0.3041 & 1.560 & -0.026 & $0.03^{* *}$ & $0.055^{*}$ \\
\hline Excess Return & -0.077 & -0.027 & 1.590 & 0.067 & $0.029^{* *}$ & 0.18 \\
\hline Log IRR & -0.4931 & -0.3626 & 0.2463 & -0.0265 & $0.021^{* *}$ & $0.055^{*}$ \\
\hline Log Excess Return & -0.4361 & -0.238 & 0.282 & 0.068 & $0.020^{* *}$ & 0.18 \\
\hline
\end{tabular}

Table 6: Performance until Exit and Exit Hierarchy. Observations are observed exits in the Venture Economics sample of 233 randomly US companies and all observed exits of European companies in Venture Economics with exit valuations, respectively. Companies had a first valuation stage after 1997, at least one stage labeled as seed or early stage or were not more than 3 years old at the first round. We excluded observations with a total duration from first round to exit of less than 3 months (IPOs) or less than 4 months (trade sales). The tests are two-sided t-tests for differences in sample means (unequal variances according to Satterthwaite's method) and a Wilcoxon signed rank test for medians. $t$-statistics in brackets. Levels of significance: ${ }^{*}=10 \%,{ }^{* *}=5 \%,{ }^{* * *}=1 \%$, $* * * *=0.1 \%$. 